\title{
Diabetic hemichorea-hemiballismus with nonketotic hyperglicemia: a rare cause of hyperkinetic movement disorders
}

Hemibalismo-hemicoreia associada à hiperglicemia não-cetótica: uma rara causa de distúrbios hipercinéticas do movimento

Lucas Giansante Abud1,2, Thiago Giansante Abud ${ }^{1,3}$, Rodolfo Mendes Queiroz', Giovanni Salton Pietroni', Daniel Giansante Abud ${ }^{4}$

A 67-year-old woman was admitted with right hemichorea-hemiballismus. Blood glucose: $831 \mathrm{mg} / \mathrm{dl}$. Magnetic resonance imaging (MRI) showed signal change in the left striatum (Figures 1 and 2).

This entity is characterized by hyperintensity confined to the striatum on T1-weighted MRI and contralateral hyperkinetic movement disorders in diabetic patients (type 2) with non-ketotic hyperglycemia ${ }^{1}$. T2*-weighted gradient-echo MRI can reveal low signal intensity related to petechial hemorrhage $^{2}$. Pathological studies demonstrated selective neuronal loss, gliosis, reactive astrocytosis and hemorrhage ${ }^{3}$.

The clinical symptoms usually improve markedly following the correction of hyperglycemia. Thus, the prompt recognition of this potentially treatable disease is of paramount importance.
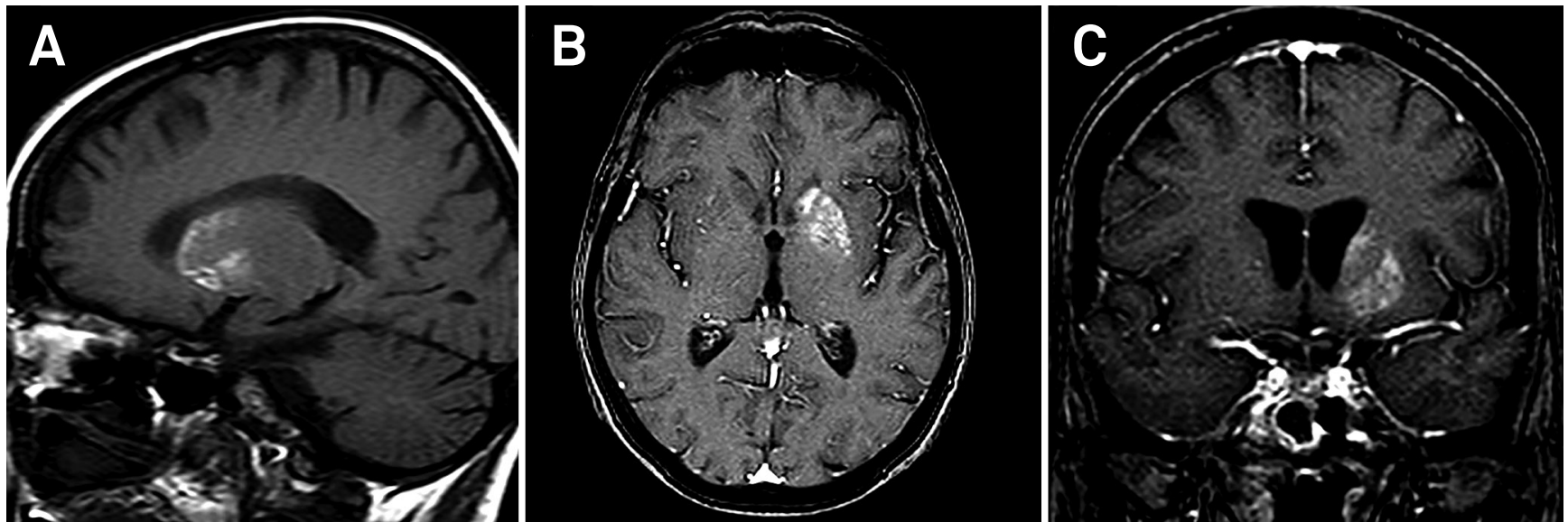

Figure 1. A) Sagittal T1- weighted magnetic resonance imaging showing spontaneous diffuse high intensity of the left striatum (caudate nucleus and putamen). B and C) There is no significant enhancement on axial and coronal T1-weighted MRI after intravenous paramagnetic contrast administration.

\footnotetext{
'Documenta, Hospital São Francisco, Divisão de Neurorradiologia, Ribeirão Preto SP, Brazil;

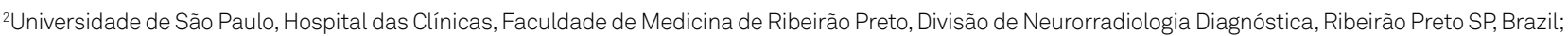
${ }^{3}$ Universidade Federal de São Paulo, Departamento de Radiologia, São Paulo SP, Brazil;

${ }^{4}$ Universidade de São Paulo, Hospital das Clínicas, Faculdade de Medicina de Ribeirão Preto, Divisão de Neurorradiologia Intervencionista, Ribeirão Preto SP, Brazil. Correspondence: Lucas Giansante Abud; Avenida Heráclito Fontoura Sobral Pinto, 751,,CEP:14022-000, Ribeirão Preto SP, Brasil; E-mail:abud.lucas@gmail.com Conflict of interest: There is no conflict of interest to declare.
}

Received 06 July 2015; Received in final form 01 October 2015; Accepted 20 October 2015. 

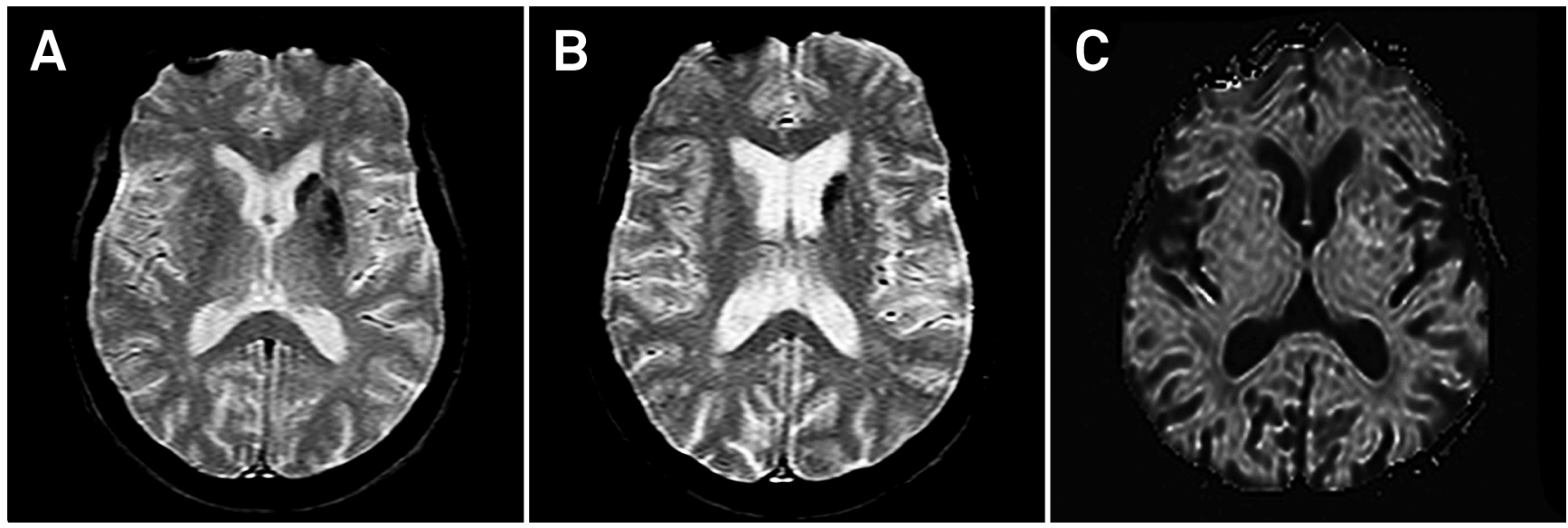

Figure 2. A and B) Axial T2*-weighted gradient-echo MRI showing multiple confluent foci of hypointensities in left striatum probably due to petechial hemorrhage. C) There is no significant signal change on axial diffusion-weighted image.

\section{REFERENCES}

1. Lai PH, Tien RD, Chang MH, Teng MM, Yang CF, Pan HB et al. ChoreaBallismus with nonketotic hyperglycemia in primary diabetes mellitus. AJNR Am J Neuroradiol. 1996;17(6):1057-64.

2. Suto Y, Mori M, Kagimoto H, Saito J. [A case of hemichorea with hyperglycemia presenting with low signal intensity in the striatum on T2*-weighted gradient-echo magnetic resonance imaging]. Rinsho Shinkeigaku. 2004;44(2):86-90. Japanese.
3.

Abe Y, Yamamoto T, Soeda T, Kumagai T, Tanno Y, Kubo J et al. Diabetic striatal disease: clinical presentation, neuroimaging, and pathology. Intern Med. 2009;48(13):1135-41. doi:10.2169/internalmedicine.48.1996 